\title{
Língua portuguesa como marca distintiva: uma escola de identidade timorense na ocupação indonésia ${ }^{1}$
}

\author{
Ângelo Ferreira² \\ ORCID: 0000-0003-1327-7140
}

\section{Resumo}

Os timorenses lutaram durante 24 anos (1975-1999) contra a violenta ocupação indonésia e o esforço educativo para os indonesiar. Esta pesquisa, um estudo de caso sobre o Externato de São José (ESJ) para compreender o propósito de manter o ensino em língua portuguesa (LP), quando esta foi proibida e perseguida por atrasar a integração efetiva na Indonésia, segue uma metodologia qualitativa, sob o paradigma interpretativo. Para compreender com maior profundidade os objetivos da escola, decidiu-se ouvir os seus principais agentes e testemunhas privilegiados, realizando uma análise de conteúdo de dez entrevistas semiestruturadas com antigos estudantes, professores e membros da sociedade. A pesquisa reforça a ideia de que a identidade é sedutora, de que ela depende da adesão das pessoas e projeta a sua pertença a algo maior, a um povo com uma cultura singular, cujo idioma, em articulação com outros aspetos culturais, tem um papel decisivo. Os resultados mostram 124 ocorrências que evidenciam a intencionalidade da escola na promoção da LP como marca distintiva da identidade timorense, sendo destacada pelos entrevistados como essência dessa identidade, como rejeição da língua indonésia (LI) e da integração cultural ou como repositório da cultura timorense, de influência portuguesa ou latina. A valorização identitária consignada à LP, atribuída inclusive por pessoas com posições opostas sobre o estatuto político do Timor-Leste (pró-independência ou pró-integração na Indonésia), uniu a geração anterior educada em português e parte da juventude na luta pela independência, contrariando eventuais ambiguidades na sociedade timorense quanto ao estatuto da LP como língua oficial.

\section{Palavras-chave}

Escola - Língua portuguesa - Identidade cultural timorense - Identidade nacional - Timor-Leste.

\footnotetext{
1- Financiamento: Este trabalho é financiado: (i) por Fundos Nacionais através da Fundação para a Ciência e a Tecnologia (FCT), I.P., no âmbito do projeto UID/CED/00194/2019; (ii) pela Fundação para a Ciência e Tecnologia através da bolsa de doutoramento SFRH/BD/125360/2016, comparticipada pelo Fundo Social Europeu e Programa Operacional de Capital Humano.

2- Universidade de Aveiro, Aveiro, Portugal. Contato: angeloferreira@ua.pt
} 


\section{Portuguese language as a distinguishing mark: an East Timorese identity school during the Indonesian occupation}

\section{Abstract}

East Timorese fought for 24 years (1975-1999) against the violent Indonesian occupation and the educational effort to make them Indonesians. This research consists of a case study intended to understand the purpose of a school named Externato de São José in maintaining all teaching in the Portuguese language when it was banned and persecuted for delaying effective integration in Indonesia during that period. A qualitative methodology is used under the interpretive paradigm. In order to better understand this school's objectives, it was decided to listen to its privileged witnesses, carrying out a content analysis of ten semi-structured interviews with former students, teachers, and members of society. The research undertaken reinforces the idea that identity is seductive, that it depends on people's free adhesion, and projects a sense of belonging to something bigger, to a people with a unique culture, with language, in conjunction with other cultural features, playing a decisive role. Results show 124 occurrences illustrating the school's aim in promoting the Portuguese language as a distinguishing hallmark of East Timorese cultural identity, being highlighted by the interviewees as the essence of their identity, as a rejection of Indonesian language and cultural integration in Indonesia, or as a recovery of East Timor culture, of Portuguese/Latin influence. This central identity role given to the Portuguese language, either by pro-integration in Indonesia and pro-independence supporters, unified the older generation educated in Portuguese and part of the youth in the struggle for independence, thus contradicting any lasting uncertainties in East Timor society regarding the status of Portuguese as one of the two official languages.

\section{Keywords}

School - Portuguese language - East Timorese cultural identity - National identity East Timor.

\section{Introdução: uma escola contra a indonesiação}

O Timor-Leste esteve sob a influência de Portugal durante séculos. Após a queda do Estado Novo, as colônias portuguesas tornaram-se independentes. Contudo, num contexto de guerra civil fratricida, de ambição territorial da Indonésia e de clima internacional de Guerra Fria, aquele território sob administração portuguesa (para o direito internacional) foi invadido pela Indonésia em dezembro de 1975, com o apoio de países aliados (e.g. 
Austrália e Estados Unidos da América). 0 argumento mais disseminado residia na necessidade de travar a potencial escalada do comunismo na região, que então representava um dos partidos majoritários, a Frente Revolucionária de Timor-Leste Independente (MAGALHÃES, 1999; MATTOSO, 2005; PIRES, 2013).

No processo de descolonização, iniciado por Portugal, as questões da identidade nacional timorense se evidenciaram. Entre os mais de vinte grupos etnolinguísticos, a maioria da população se comunicava razoavelmente em tétum-praça, língua franca cujo léxico bebe do tétum antigo e do português (THOMAZ, 2002); a classe política, posicionando-se contra o colonialismo, não rejeitava a língua portuguesa (LP), considerada por todos elemento ancestral e parte integrante da identidade timorense, inclusive pelo partido minoritário que visava a integração na Indonésia (HULL, 2001). Porém, a afirmação nacional foi interrompida pela invasão indonésia. Só em 1999, sob os auspícios da Organização das Nações Unidas (ONU), os timorenses decidiram, em referendo, o seu estatuto político, tendo 78,5 por cento dos votos a favor da independência, formalizada em 2002. Nesse ano, a Assembleia Constituinte aprovou a Constituição da República Democrática de Timor-Leste (2002), assumindo, a par do tétum, a LP como língua oficial, reiterando as posições políticas de 1975.

Durante a ocupação, a LP e os vestígios das relações com a cultura de origem portuguesa foram perseguidos: "os militares indonésios faziam rusgas [...] revistando malas, armários de roupas e da cozinha, quartos [...]. Destruíam livros portugueses, cassetes com músicas portuguesas e fotografias de timorenses com amigos e colegas portugueses" (GUTERRES, 2014, p. 361-362). 0 Estado focou-se em indonesiar os timorenses, tornando obrigatória a aprendizagem do indonésio e do Pancasila - os cinco fundamentos filosóficos e políticos do Estado indonésio -, com base em um currículo e materiais didáticos iguais aos das outras províncias, para assegurar a unidade nacional (BECK, 2008; XIMENES BEL0, 2008). A Igreja Católica, pioneira na educação através da abertura de escolas pelos dominicanos, manteve um papel relevante, mas suas escolas adotaram o currículo e a língua indonésia. 0 ensino em

[...] Língua Portuguesa foi banido, com exceção do Externato de São José [escola diocesana de Díli], que funcionou até 1992, altura em que foi dada ordem de encerramento. [...] Houve mesmo casos em que os jovens eram agredidos por saudar os clérigos com um "Bom-dia, senhor padre!" (XIMENES BELO, 2008).

O Externato foi a única escola que manteve o ensino todo em português, "remando contra a corrente e a ordem estabelecida pelos indonésios que impunham a língua indonésia nos domínios: escolar, administrativo, social" (FELGUEIRAS; MARTINS, 2006, p. 88-89).

Essa persistência dos padres fundadores Leão da Costa e Domingos da Cunha, assim como os professores, famílias e estudantes num ensino em LP é pouco conhecida e nunca foi estudada e devidamente apreciada, até porque, se não fosse aquela escola, "hoje não tínhamos timorenses competentes e bem formados que ocupam lugares importantes na sociedade timorense, como Ministros, Reitores de Universidades etc." (FELGUEIRAS; MARTINS, 2006, p. 89). 
A escola só se manteve aberta entre 1977 e 1992 por pertencer à Igreja e cair na superintendência do Vaticano, o que impediu as autoridades indonésias de encerrá-la mais cedo. No seguimento do Massacre de Santa Cruz, episódio em que militares indonésios mataram centenas de jovens que depunham flores na campa de um jovem independentista assassinado uns dias antes por agentes pró-integração, as autoridades conseguiram a anuência da Igreja para fechá-la. 0 argumento era que ela produzia jovens responsáveis por organizar ações e manifestações anti-Indonésia, como aquela marcha ao cemitério, pautada por uma manifestação contra a presença indonésia e a favor da independência (TEMP0, 1991).

0 desígnio de estudar a escola consolidou-se quando foi confirmado, por um dos fundadores, que o objetivo era resistir à ocupação cultural indonésia, através de "uma escola católica, nacionalista e lusófona" (informação verbal) ${ }^{3}$, reiterando aquilo que já havia sido escrito pelo jesuita português que ali ensinou: "Foi um 'milagre' que tivéssemos conseguido manter tantos anos esta escola de formação lusófona, cristã e nacionalista” (FELGUEIRAS, 2001, p. 48). Foram ainda decisivas as inúmeras alusões feitas por timorenses, notáveis ou anônimos, nas visitas regulares que fizemos ao país nas duas últimas décadas, no âmbito da cooperação internacional no setor educativo, destacando a relevância da escola para a independência e para a edificação do estado-nação, dado o papel notável dos seus graduados (e.g., ministros em vários governos, um primeiro-ministro, docentes universitários, reitores, deputados, embaixadores, ativistas e profissionais destacados).

Este artigo, que resulta da pesquisa para um doutorado em Educação sob o título "Escola, identidade e resistência em Timor: o caso do Externato de São José durante a ocupação indonésia”, procura compreender com maior profundidade o papel da LP no propósito da escola de promover uma distintiva identidade timorense, partindo da abordagem teórica do tema da identidade cultural, em particular do papel da língua, em sequência, apresentação da metodologia seguida, caraterização do grupo de entrevistados, apresentação dos principais resultados da análise de conteúdo e, por fim, considerações finais.

Considerando que o tema tratado neste artigo, o papel desempenhado pela LP na identidade cultural timorense, tem sido muito politizado recentemente, julgamos que ele merece um estudo sereno. Portanto, o autor procurará ater-se aos fatos, ainda que eles sejam, naturalmente, declarações passionais dos entrevistados.

\section{Identidade cultural: em torno do valor e do sentido}

A questão das identidades culturais nacionais tem suscitado polêmica no meio acadêmico e no espaço público, por razões de ordem conceitual e ideológica. A tensão tem sido proporcional ao valor que o tema tem para a compreensão da ação humana, como destacadamente problematizaram Gellner (1993), Hobsbawm e Ranger (1984) ou Smith (2015a, 2015b). A identidade é um tópico muito sedutor porque

[...] traz para a imaginação sociológica os dramas mundanos, os sonhos e as perplexidades da vida quotidiana. [...] a "identidade", como um meta-conceito que tanto faz sentido individualmente

3- Conversa entre o fundador e diretor do Externato de São José, Pe. Leão da Costa, e Ângelo Ferreira sobre os fundamentos da escola, 15 de maio, 2014. 
quanto coletivamente, é estrategicamente significativa para o debate estrutura-ação na teoria social. (JENKINS, 2004, p. 4).

Por isso, Fearon (1999) sublinhou que as questões da identidade são de interesse crescente nos domínios do conhecimento que têm procurado compreender quem somos e como nos relacionamos, somando-se aos posicionamentos ideológicos a dificuldade em definir o próprio conceito de identidade, complicado e ambíguo. Neste quadro, considera-se, como sugere Almeida (2002), a declaração de Thomas Reid sobre a identidade individual, por ser, em termos fundamentais, generalizável:

Se pedem uma definição de identidade, confesso que não posso dar nenhuma; é uma noção demasiado simples para admitir uma definição lógica. Posso dizer que é uma relação, mas não consigo encontrar palavras para expressar a diferença específica entre esta e outras relações, embora eu não corra o perigo de confundi-la com outra qualquer. (REID, 1875, p. 377).

A identidade é central na questão das civilizações, das nacionalidades e das migrações, na gestão das relações internacionais e internas, no modo como os povos (as culturas) se relacionam e procuram a paz, como afirma Berenskoetter (2017). Por isso, Hopf (1998) considerava as identidades necessárias para evitar a anarquia e o caos, garantindo um certo nível de previsibilidade nas relações. Na verdade, "se aceitarmos que existe uma 'vontade de manifestar identidade', então os processos pelos quais se definem as fronteiras, [...] como a identidade nacional, devem ser considerados uma dimensão central da política internacional” (BERENSKOETTER, 2017, p. 3607). As identidades culturais nacionais são elaborações discursivas, metáforas, e não um código genético, ainda que pensemos nas nacionalidades como parte da nossa natureza, que nos confere sentido: "As culturas nacionais constroem identidades quando produzem sentidos sobre a 'a nação' com a qual nos podemos identificar; estes estão contidos nas estórias contadas sobre ela, memórias que ligam o seu presente com o seu passado" (HALL, 1996, p. 611-613).

0 tema é atual, importante e transversal, como mostra a reflexão levada a cabo pelo conservador Scruton e pelo liberal Gellner. 0 primeiro, preferindo falar de sentimento nacional (e patriotismo), defende que a própria condição do ser humano requer que o indivíduo, ao atuar como ser autônomo, o faz porque se identifica com algo maior, como membro de um grupo, sociedade ou nação, mesmo que não consiga atribuir nome a esse dispositivo que "reconhece instintivamente como lar" (SCRUTON, 1980, p. 34). 0 segundo acredita que, sem essa identificação nacional, o sujeito moderno experimentaria um profundo sentimento de perda subjetiva, pois apesar de a nacionalidade não ser "uma característica inata do ser humano [...] chega realmente a parecê-lo” (GELLNER, 1993, p. 18).

Por tudo isso, é inevitável que os temas da identidade nacional e do nacionalismo se entrecruzem, até porque a maior polêmica relaciona-se com a existência de visões mais extremistas. Proeminentes estudiosos sobre nacionalismo, como Smith (1979), Calhoun (1993) e Mayall (1993), sublinharam a necessidade da sua compreensão para a paz, domando os seus excessos, verificada a persistência de um sistema mundial baseado em estados, apesar de todas as organizações supranacionais, e dado não ter ainda aparecido uma lealdade humana mais forte 
ou um princípio legitimador da organização política do Estado moderno capazes de transcender o ideal nacional.

A identidade tem um lado luminoso e outro sombrio. Já motivou atrocidades quando associada à ideia de essência, de superioridade e de subjugação. Veja-se o que aconteceu na Segunda Grande Guerra, em particular com o extermínio de judeus, com a imposição de todo tipo de totalitarismos, com a violência racial (sem diminuir qualquer outra, o Apartheid na África do Sul ou o quase extermínio de indígenas na Austrália), com as guerras internas na África após conquistas de independência, ou com o jihad islâmico, assentes em argumentos étnicos, religiosos ou ideológicos. A ação com base numa visão essencial e imutável da identidade representa um recuo humano, originando conflitos, pois a diferença torna-se uma ameaça que gera insegurança, e a segurança apenas se garante "pela separação ou pela subjugação" (GILROY, 1997, p. 315). Mas a identidade foi também argumento para a libertação de povos oprimidos, como se observa no caso de Timor-Leste. Berque (1978) e Guibernau (1997) evidenciam que, num mundo carregado de ambiguidade e fragmentação, em que as ideologias deixaram de dar sentido à empresa humana, a identidade coletiva cria um sentido de pertença e uma solidariedade decisiva para o bem-estar e a paz. As preocupações de muitos cientistas sociais com os desmandos nacionalistas tendem a destacar a imposição de interesses culturais, econômicos e políticos, mas "ignoram a substância nacional e moral das exigências nacionalistas de minorias que reclamam o direito de existir, ser respeitadas, desenvolver sua própria cultura e identidade" (GUIBERNAU, 1997, p. 154-155). Por outro lado, não existe antagonismo entre a existência de diferentes identidades e um concerto pacífico das nações, como refere Gellner (1993, p. 1213), assumindo a defesa do princípio nacionalista "num espírito ético e "universalista", sem a superioridade de qualquer nacionalidade.

0 ressurgimento da ideia de nação, segundo Castels (2010), surprendeu os observadores que anteriormente a declararam defunta por morte tripla: por asfixia pelas mãos da globalização da economia e das instituições políticas universais; pelo universalismo de uma cultura difundida e partilhada por todos; e pelo ataque erudito ao próprio conceito de nação, numa versão anti-nacionalista moderada, como a de Anderson (2006), que declara as nações como "comunidades imaginadas". Ora, convém reter, com Lipiansky (1991), que a identidade é um fenômeno subjetivo, uma imagem de si mesma, representação e sentimento, na base da comunidade e de sua coesão, edificando-se no "confronto" com o outro, sobretudo quando o outro pode ser uma ameaça à integridade da comunidade. Real ou ilusória, a identificação coletiva gera imagens poderosas e apela à ação, fortalecendo-se na evocação simultânea da diferença, pois estabelecer um "nós” implica definir uma gama de "eles”, sendo que, na fronteira partilhada, descobrimos o que somos e não somos, como explica Jenkins (2004).

\section{A língua como principal marca distintiva}

Steiner (1992) advoga que a separação das línguas permite que os diferentes grupos falantes mantenham em segredo as fontes de identidade herdadas e singulares, preservando perspectivas distintas sobre a realidade e protegendo o caráter distintivo do grupo. Por isso, defende Edwards (1985), a língua pode ser um veículo de ocultação, sigilo e ficção, mantendo inviolado o entendimento que o grupo tem do mundo e alimentando 
o sentimento patriótico com seu poderoso simbolismo. Steiner (1992) aponta que o valor simbólico, as associações históricas e culturais que a língua acumulou e uma "natural semântica da memória" acrescentam à mensagem uma rica sustentação em "conotações partilhadas", garantindo ao grupo uma exclusiva capacidade de ler nas entrelinhas.

No início do século passado, Barker (1927, p. 13) considerara que a "nação é tradição de pensamento e de sentimento, [que] têm profunda congruência com o discurso, [havendo] uma relação próxima entre nação e língua”, esta escondendo associações que tocam sentimentos e pensamentos, apenas partilhados por quem tem a chave interpretativa. 0 autor diz ainda que a cristianização, feita inicialmente em grego, trouxe muito do pensamento grego para a cristandade, e depois para a língua da disseminação, o latim. Assim entrou, juntamente com a qualidade latina e a sua tradição, no vocabulário e na identidade cultural de línguas europeias, cuja base lexical deriva do latim, como é o caso do inglês, mas mais ainda do português. Talvez seja por isso que os movimentos nacionais comecem, em boa medida, pelo ressuscitar de uma língua na qual procuram a velha alma da nação, que se esconde na profundidade do discurso. Já Vygotsky (1978) sublinhara que a língua não era apenas ferramenta técnica, mas carregava as caraterísticas do contexto em que se desenvolveu, cuja internalização distinguia o ser humano de outros animais, e, assim, separava a psicologia animal da psicologia humana. Por isso, as decisões políticas sobre a(s) língua(s), um artefato cultural "no qual valores culturais, histórias, tradições e crenças estão incorporados” (TSUI; TOLLEFSON, 2007, p. 9), são centrais para qualquer país, por terem um impacto muito grande sobre as identidades nacionais. Cada nação tem um universo simbólico, abrangendo valores e normas, como principal fonte de legitimidade do poder político e garantia da ordem social, controlando a conduta e dando sentido à realidade, que é apropriado e reproduzido pelos indivíduos por meio da "mais poderosa marca de identidade - a língua nacional” (LIPIANSKY, 1979, p. 11). Na sua versão moderna, o nacionalismo, segundo Kedourie (1998), está ligado à escolha de uma língua nacional, vista como uma evidência externa da identidade específica de um grupo e elemento decisivo para garantir sua continuidade.

Aludindo às origens germânicas da tendência para ver na língua um caráter ou mesmo uma espécie de espírito (Humboldt e Herder), assim como à hipótese dos autores Sapir e Whorf, que atribui a cada língua uma visão de mundo intraduzivel para qualquer outra, Almeida (2017) aceita que existem nuances intraduziveis, mas contesta referências à língua como condicionante do pensamento e da visão do mundo. A língua, sendo o repositório das experiências culturais de um povo e reflexo das suas mundividências, dos universos particulares de seus falantes, carregados de semânticas específicas partilhadas apenas por alguns, desenvolveu-se "à medida que foram surgindo realidades novas que precisavam de ser nomeadas” (ALMEIDA, 2017, p. 108). Desse modo, a língua permite estabelecer redes de contato entre seus falantes, inclusive de regiões distintas, como acontece na Comunidade dos Países de Língua Portuguesa (CPLP), valorizandose os aspectos positivos da história comum, da miscigenação, do contágio cultural, da cooperação e do potencial futuro.

Apesar de haver estados com mais do que uma língua oficial e estados que partilham entre si a mesma língua, Thiesse (2000) chama a atenção para a importância do modelo "uma 
língua, uma nação", que dá ênfase ao princípio herderiano da encarnação da nação em sua língua, assumindo também a função de substituir uma miscelânea de modalidades linguísticas que respondiam a utilizações diversificadas. Nesse quadro, a escola constitui peça-chave no dispositivo de nacionalização geral, pois nela se aprende, para além da geografia, da história e de ser e pensar nacionalmente, a língua, e tudo se aprende nessa língua.

Para os objetivos deste artigo, sobre o propósito da escola quanto à promoção da identidade, a grande questão, como afırma Guibernau (1997), relaciona-se com a identidade que cada um pensa ter, uma interpretação do "eu", que define o que é e onde está (do ponto de vista psicológico e sociológico), situando a pessoa quanto às relações sociais e às filiações, cujo critério passa por uma comparação com os outros e por uma certa continuidade no tempo. Ainda que sejam realidades comunicantes, de acordo com Almeida (2002), é preciso distinguir entre o “carácter nacional”, que é o autoconhecimento que um grupo procura ter de si mesmo, um exercício racional para compreensão da realidade, e a "identidade cultural ou nacional", que pertence ao reino das emoções e depende da adesão a identificações, podendo um indivíduo ter todas as características que nos levariam a colocá-lo num determinado grupo, com o qual, por qualquer motivo, não se identifica. Esta centralidade ao que os próprios sentem, como parte de algo maior em termos identitários, é mais interessante do que atribuir-lhes rótulos a que não adiram, e mais decisiva para entender a sua ação como grupo (nação).

\section{Percurso metodológico: questionando os próprios}

Numa época em que a LP era perseguida e a língua indonésia (LI) se massificava, uma escola decidiu persistir no ensino em LP como forma de promover uma determinada identidade e rejeitar a integração em outra. Assim, a questão que se coloca é: quais são as representações atuais de antigos alunos e antigos professores, observadores privilegiados do funcionamento do Externato de São José (ESJ), sobre o papel da LP no âmbito do propósito daquela escola? 0 correspondente objetivo consiste em identificar e classificar ideias-chave sobre o papel da LP enquanto marca distintiva da identidade timorense (e rejeição da indonesiação).

Considerando o objeto de estudo, a questão de investigação e o objetivo definido, aplicou-se, quanto à recolha e ao tratamento de dados, um método de natureza qualitativa. Segundo Pardal e Lopes (2011), sendo um estudo de caso, que analisa intensivamente uma situação particular, não se pretende fazer generalizações empíricas, mas antes, ser descritivo e focado no objeto. 0 trabalho está balizado no paradigma interpretativo, por colocar a tônica na qualidade da entidade estudada (o ESJ e a sua ação entre 1977 e 1992), nos processos e significações, não experimentáveis nem mensuráveis; e por dar ênfase à construção social do conhecimento, com um melhor entendimento dos contextos locais, da íntima relação entre o investigador e o que é estudado, e dos constrangimentos situacionais que dão forma à investigação, permitindo ao leitor a sua reinterpretação em novos contextos (AMAD0, 2013; GUERRA, 2006; WILLIS, 2008).

Conforme Stake (2012), a compreensão das complexas inter-relações entre o que existe orienta as perguntas de investigação para casos ou fenômenos, procurando padrões de relações imprevistas, mas também esperadas. Partindo-se do princípio de que os 
sujeitos interpretam as situações, concebem estratégias, mobilizam recursos e agem em função dessas interpretações, o objeto de análise é formulado em termos de ação, mas na interpretação do seu significado e não do comportamento em si próprio (BOGDAN; BIKLEN, 1992; GUERRA, 2006). Como sublinham Amado e Freire (2013), o estudo de caso é um estudo em profundidade da realidade, que enfatiza a interpretação em contexto, admite múltiplas fontes de informação, abordagens e técnicas, e busca captar a complexidade de um caso singular, com valor por si mesmo, refletindo a perspectiva dos participantes, por vezes em conflito.

Considerando o propósito deste artigo, seguimos Almeida (1991) quando considera que é mais importante identificar as ideias-chave emergentes sobre a identidade preconizada pela escola do que fazer o debate teórico de conceitos como identidade cultural ou identidade nacional. Interessou-nos identificar nas concepções atuais dos entrevistados as ideias-chave sobre o papel da LP na construção de uma identidade distintiva que os promotores e membros da comunidade escolar do ESJ decidiram promover num contexto identitário complexo. Foram realizadas entrevistas semiestruturadas com antigos alunos e professores, e com observadores privilegiados da escola (o observado por outros, sob múltiplas perspectivas), o que pode constituir uma maisvalia metodológica (GUERRA, 2006; PARDAL; LOPES, 2011), sobretudo em culturas marcadas pela oralidade (CROSSLEY; VULLIAMY, 1997), como a timorense. Como refere Coutinho (2016), a entrevista, em particular a semiestruturada, pode levar o pesquisador a classificações não previstas na conceptualização e nas hipóteses originais, porque pode ser uma poderosa ferramenta de obtenção de dados, que dificilmente se obteriam pela consulta de documentos ou mesmo por questionários fechados, sobretudo dado o contexto de secretismo em torno do propósito da escola e de toda a delicadeza que o assunto conserva. 0 roteiro da entrevista foi previamente validado por dois pesquisadores seniores. A preocupação com a validade e a fidelidade da informação recolhida fez com que, num momento anterior ao início das entrevistas, fosse comunicado ao entrevistado o enquadramento e os objetivos da pesquisa, solicitando o consentimento para a gravação e a total sinceridade, assegurando total liberdade de expressão, confidencialidade e anonimato, e, ainda, que todas as percepções são válidas e importantes para a pesquisa, não existindo respostas certas ou erradas.

Para este trabalho, foi realizada a análise de conteúdo em dez entrevistas - cujas transcrições foram validadas pelos próprios entrevistados. 0 conjunto de entrevistados foi reunido pela técnica de amostragem "bola de neve", que utiliza cadeias de referência (informantes-chave, nomeados sementes) para localizar pessoas com o perfil desejado, que tem a vantagem de permitir chegar a elementos de uma população cuja identificação e cujo acesso não é fácil. Houve ainda a preocupação de iniciar a identificação através do contato com sementes que permitissem, através do acesso a diferentes redes, encontrar a maior representatividade possível (VINUTO, 2014). Das dez entrevistas, oito foram realizadas presencialmente e duas por videoconferência, utilizando as novas tecnologias de comunicação (WhatsApp ${ }^{\mathrm{TM}}$ e Skype $\mathrm{S}^{\mathrm{TM}}$ ). Todas as entrevistas decorreram em ambiente tranquilo, e todos os entrevistados mostraram empenho na pesquisa.

Seguindo Coutinho (2016), após leitura flutuante e exaustiva dos dados, visando captar padrões de informação relevante que permitam descrever e compreender o fenômeno em estudo, procedeu-se à categorização, codificação e análise dos dados, numa abordagem que, embora tivesse partido de ideias prévias sobre hipotéticas categorias, 
considerou, através de um processo misto, indutivo e dedutivo, aquelas que emergiram dos próprios dados. Foram estabelecidas oito subcategorias para uma categoria de análise ("lingua portuguesa é marca distintiva da identidade timorense"), no âmbito de uma das dimensões de análise do estudo mais geral, neste caso o "propósito da escola", considerado como o objetivo da escola para além da oferta de uma educação e formação de qualidade, o que, no âmbito do estudo alargado, foi considerado noutra dimensão de análise relativa à caraterização da escola. Para validação da categorização realizada, foram consultados quatro pesquisadores experientes, um dos quais sênior, em áreas distintas no âmbito da educação, das línguas às ciências naturais. Não foi identificada nas transcrições nenhuma fala de pendor negativo, isto é, que pudesse contradizer as afirmações positivas dos diversos entrevistados nas diferentes subcategorias da análise.

A confidencialidade e o anonimato são garantidos, sendo os entrevistados (e as suas falas) apenas classificadas com um código que indica a ordem da entrevista no conjunto geral, caso se trate de mulher (M) ou homem (H), depois, de antigo aluno (AA), antigo professor (AP) ou membro da sociedade (MS), terminando com a ordem da entrevista nesse grupo (e.g. 28HMS01, vigésimo oitavo entrevistado, homem, membro da sociedade e primeiro entrevistado desta tipologia).

\section{Caraterização geral dos entrevistados}

Embora não constitua uma variável do estudo, é importante para a leitura dos resultados fazer uma descrição geral do perfil dos entrevistados. A escolha residiu em antigos professores (2) e antigos alunos (7), sujeitos que conheceram a escola por dentro e, ainda, um observador externo, que teve papel e funções de relevo na luta armada e tinha contato, na época, com alunos da escola.

Dos dez entrevistados seis são homens, quatro são mulheres; sete viviam em TimorLeste na data da entrevista, um em Macau (China), um no Reino Unido e outro na Austrália. Tendo nascido entre 1936 e 1969, portanto todos estavam com idades entre os 50 e os 83 anos, sendo que a maioria nasceu na segunda metade da década de 1960. Dentre os sete antigos alunos, seis concluíram formação superior em nível de licenciatura, três na Indonésia, dois em Portugal e um em Timor-Leste, tendo dois deles concluído o mestrado, um no Japão e outro na Nova Zelândia. Os sete antigos alunos desenvolvem atividades profissionais de relevância (médicos, professor universitário, tradutor/intérprete, técnico superior, ativista em organizações não governamentais). Em termos de atividade sociopolítica, destacamse antigos alunos e professores (ministros em vários governos do Timor-Leste, dirigentes partidários e indivíduos com ativismo social e público notório). Os dez entrevistados afirmam dominar várias línguas, de três a seis, incluindo sempre o português.

\section{Da análise de conteúdo para os resultados}

0 que dizem os AP, AA e MS quando questionados sobre o porquê do ensino e demais atividades da escola decorrerem em LP naquele período de ocupação indonésia no Timor-Leste? As falas sobre a importância e o papel da LP ora são respostas diretas a esse 
questionamento e, nesse quadro, sobre o seu papel na identidade timorense, ora ocorrem espontaneamente em outros momentos da entrevista em contexto relativo ao porquê da escolha da língua de ensino e do seu papel no propósito da escola, pressuposto que preside ao trabalho e é explicitado no início das entrevistas.

Após uma análise exaustiva dos dados, foram estabelecidas oito subcategorias para a categoria "língua portuguesa é marca distintiva da identidade timorense", a saber: 1) língua portuguesa é amplamente utilizada na escola; 2) língua portuguesa é repositório de cultura mista; 3) língua portuguesa é coração da identidade timorense; 4) língua portuguesa é diferença na região; 5) língua portuguesa é rejeição da língua indonésia e da integração cultural; 6) língua portuguesa é afırmação de dignidade; 7) língua portuguesa é laço político e afetivo internacional; e 8) língua portuguesa é futuro. A distribuição de ocorrências pode ser vista na Tabela 1 .

Tabela 1- Número de entrevistados que se referem positivamente a cada subcategoria e número de ocorrências para cada subcategoria, totalizando 124. Não houve quaisquer referências negativas

\begin{tabular}{|c|c|c|}
\hline \multirow[b]{2}{*}{ Subcategorias (descritores) } & \multicolumn{2}{|c|}{ Entrevistados/0corrências } \\
\hline & $\begin{array}{l}\mathrm{N} .{ }^{\circ} \text { entrevistados que } \\
\text { referem positivamente }\end{array}$ & N. ${ }^{\circ}$ ocorrências \\
\hline $\begin{array}{l}\text { 1. Língua portuguesa é amplamente utlizada na escola (a língua é usada em todas as } \\
\text { situações, para aprender, pensar, exprimir, conviver) }\end{array}$ & 7 & 15 \\
\hline $\begin{array}{l}\text { 2. Língua portuguesa é repositório de cultura mista (a língua transporta a fusão de } \\
\text { culturas) }\end{array}$ & 7 & 20 \\
\hline $\begin{array}{l}\text { 3. Língua portuguesa é coração da identidade timorense (a língua é essência, } \\
\text { patrimônio íntimo comum, o que pode ser independente de as pessoas serem pró- } \\
\text { Indonésia ou independentistas) }\end{array}$ & 9 & 27 \\
\hline $\begin{array}{l}\text { 4. Língua portuguesa é diferença na região (a língua é a principal marca distintiva } \\
\text { e de singularidade em relação aos povos da região onde Timor-Leste se insere, em } \\
\text { particular em relação ao povo da parte indonésia da ilha) }\end{array}$ & 8 & 13 \\
\hline $\begin{array}{l}\text { 5. Língua portuguesa é rejeição da língua indonésia e da integração cultural (o domínio } \\
\text { exclusivo da língua portuguesa é símbolo e instrumento de resistência à anexação do } \\
\text { país, até por garantir o segredo das fontes de identidade e das comunicações) }\end{array}$ & 9 & 27 \\
\hline $\begin{array}{l}\text { 6. Língua portuguesa é afirmação de dignidade (o domínio exclusivo da língua garantia } \\
\text { um sentimento de dignidade a par ou acima do invasor que humilhava) }\end{array}$ & 3 & 6 \\
\hline $\begin{array}{l}\text { 7. Língua portuguesa é laço político e afetivo internacional (a língua como fator de } \\
\text { união com outros povos e populações em todos os continentes, em particular com } 0 \\
\text { povo português) }\end{array}$ & 6 & 12 \\
\hline $\begin{array}{l}\text { 8. Língua portuguesa é futuro (a língua vista como o futuro de Timor-Leste, } \\
\text { independentemente do seu estatuto político) }\end{array}$ & 4 & 4 \\
\hline
\end{tabular}

Fonte: Dados da pesquisa. 
Um número significativo de entrevistados, nove de dez, refere-se às categorias 3 e 5, com 27 ocorrências em cada uma, uma média de três por entrevistado, logo seguidas da categoria 2, em que se verificam vinte ocorrências em sete dos dez entrevistados. As categorias 1, 4 e 7 aparecem relativamente próximas com referências de, respectivamente, sete entrevistados e quinze ocorrências, oito entrevistados e treze ocorrências, seis entrevistados e doze ocorrências, enquanto a categoria 8 tem apenas quatro ocorrências feitas por quatro entrevistados. A categoria 6, embora seja referida apenas por três entrevistados, ao contrário da categoria 8, registra seis ocorrências, portanto com uma média de duas ocorrências por entrevistado. Mais do que a quantidade de ocorrências, interessa compreender, neste trabalho, o sentido e a profundidade daquilo que é afirmado. Deste modo, vale a pena trazer a este artigo alguns exemplos das ocorrências mais significantes para cada uma das subcategorias em apreço.

Começando pelas subcategorias que mostram ter mais evidências e um maior número de referências pelos entrevistados, observa-se algumas ocorrências na categoria 3, que evidenciam o papel essencial da LP, vista como patrimônio comum:

[...] muitas famílias mandavam para lá os filhos, até gente que era claramente pró-Indonésia [...] exteriormente mostram-se indonésios para viver, mas acho que no íntimo são sempre timorenses, havia aquele espírito de unidade, de apoio, mesmo secreto, foi por isso que não tocaram tanto nisso, na questão do Externato e da língua portuguesa. (06HAA05).

[...] podia haver algum infiltrado, mas eram quase todos nacionalistas, também havia filhos de gente da APODETI [Associação Popular Democrática de Timor], que talvez valorizassem a cultura e a língua portuguesa, mas no fim acabavam por virar nacionalistas e até se viravam contra os próprios pais [...], às vezes assim em encontros oficiais falava tétum, mas a minha articulação do tétum, a construção, é do português. (08HAA07).

[...] é muito interessante que estas pessoas a favor da Indonésia davam proteção à escola e muitos dos altos funcionários do estado indonésio queriam aprender o português ali no Externato, o Armindo Mariano, que era um dos chefes de serviço da Educação com uma certa influência, ele estava a estudar no Externato e concluiu lá o ciclo preparatório [...]. Nós percebemos desde cedo que a cultura e a língua portuguesa eram a nossa maior riqueza, mesmo aqueles que nem estudos tinham e até nem tinham sofrido grande influência da cultura portuguesa, que pouco sabiam da língua portuguesa antes da invasão. (26HAP06).

Quanto ao fato de o ensino em LP significar rejeição da LI e da indonesiação (categoria 5), podemos salientar as seguintes ocorrências:

[...] para mim, a resistência foi mesmo estudar em português e nunca ter ido para uma escola indonésia [...]. Ensinar em português, uma forma de rejeição do que era indonésio [...]. 0 indonésio como língua era uma das disciplinas no currículo do Externato, mas fora daquela aula, não utilizávamos o bahasa indonesia, nem oralmente, nem na escrita, tudo era em português. (17MAA14). 
[...] a escola e a língua portuguesa foram um instrumento de luta contra a ocupação. (28HMS01).

[...] o ensino em língua portuguesa e uma espécie de teimosia dos timorenses em contradizer os indonésios, em resistir, porque eles obrigavam-nos a falar em indonésio [...]. A língua portuguesa era parte integrante da nossa luta [...]. Eu nunca aprendi bahasa, ninguém aceitava a anexação, por isso usávamos a língua portuguesa como barreira a essa cultura que pretendia dominar-nos. (31HAP07).

A língua é também referida como o repositório da cultura timorense ou lusotimorense, vista como encontro de civilizações e culturas:

[...] por causa desta língua, desta identidade cultural! [...] a única escola que conservava a língua portuguesa da identidade, dos valores socioculturais de um povo [...] então é por causa desta cultura, desta identidade cultural que é a língua, que permanece na nossa cultura também, como nossa cultura também. (01MAA01).

[...] na base do Externato estavam os valores da língua portuguesa e da cultura, claro, juntamente com as coisas de Timor mais antigas [...]. 0 Externato de São José foi muito importante para Timor-Leste, foi determinante na preservação [...] da língua portuguesa em Timor [...] e talvez por isso, tenha evitado uma completa alienação cultural. (02MAA02).

Alguns entrevistados sublinham a ampla utilização da língua na escola (categoria 1) para o ensino e o convívio:

[...] falávamos em português e faziamos as apresentações, os teatros e os poemas em português [...] quando vinha ali a escuridão a espreitar, nós dizíamos que aquela era uma escola portuguesa, uma escola em língua portuguesa, que era a nossa cultura [...], fazíamos (...) teatros em português, tudo. (06HAA05).

[...] tudo lá dentro era em português, as atividades, as missas, as músicas, até os escuteiros eram em português. (29HAA22).

[...] a língua falada na escola era só o português. (31HAP07).

A língua é vista como a melhor forma de marcar a diferença na região, preservando a singularidade, em particular com a outra metade da ilha (Indonésia):

[...] o que mais nos distinguia era [...] a língua portuguesa. (17MAA14).

[...] a língua portuguesa fazia parte da nossa identidade, era aquilo que nos fazia diferentes dos indonésios. (20MAA17). 
Por outro lado, o domínio da LP era percebido como fator de dignidade perante o invasor que desprezava os timorenses (categoria 6) e ainda como laço político e afetivo internacional (categoria 7), decisivo para a luta pela independência:

a língua portuguesa [...] era uma língua em que nós éramos melhores do que os indonésios e eles não percebiam nada, o que ganhava muita importância naquele contexto em que nos estávamos a sentir pessoas de segunda categoria [...]. Repare que na ocupação aquilo que nos fez sentir seres humanos e termos uma dignidade elevada foi o fato de sabermos português e eles não saberem nada! (26HAP06).

[...] as pessoas diziam que o fator determinante do ponto de vista dialético era o fator interno, mas eu por mim, em última análise, foi a sensibilização da comunidade internacional, da opinião pública internacional [...]. Nós bem que andávamos aqui a gritar mas não acontecia nada, só quando o mundo acordou para isto, nós não devíamos deixar esquecer isto, a língua portuguesa foi um marco muito importante [para esse efeito]. (28HMS01).

Por fim, alguns referem-se ao ensino da LP como elo entre o passado e o futuro, independentemente do estatuto político de Timor-Leste, o que fica bem claro nesta ocorrência:

[...] se não existisse a escola então haveria uma lacuna complicada entre duas gerações, isto é a geração antiga de 1975 que pensava, falava e escrevia em português e a nova geração, a geração da independência [...], coisa que os do Externato e outros que se juntaram a eles na luta pela liberdade souberam fazer a ponte entre gerações, a língua portuguesa teria ficado apenas com a geração antiga, como algo do passado, mas não, foi [...] assumida também pelos jovens. (29HAA22).

\section{Considerações finais}

Todos os entrevistados atribuem importante papel ao ESJ como única escola que ensinava em português no período da ocupação, afirmando a importância dessa língua como marca distintiva da identidade timorense, sem rastro de eventuais ambiguidades que possam existir na sociedade timorense sobre esse estatuto, eventualmente em virtude de a maior parte da juventude ter sido educada em LI e sob doutrinação dos valores indonésios. Esse aspecto é notável, porquanto evidencia coesão identitária entre pessoas com posições divergentes sobre o estatuto político de Timor (independentistas ou integracionistas na Indonésia), valorizando a influência da LP, que reportam estar inclusive impregnada em não falantes, tendo entrado através do léxico e, com ele, da cultura, adotados pelo tétum ao longo de séculos, língua franca disseminada pela missionação católica e utilizada para a comunicação entre grupos etnolinguísticos distintos.

No quadro de uma juventude sendo educada em LI, os dados mostram a valorização do ensino em português como aspecto que favorece a preservação, nas novas gerações, dessa identidade cultural distintiva, projetada, em união com a geração anterior falante de LP, como ligação a algo maior, a nação timorense, no sentido de defender a dignidade 
desse povo subjugado e garantir-lhe a independência. Assim, a LP aparece como coração da identidade e como instrumento de rejeição de uma identidade invasora, representada pela língua indonésia. Associada a outros traços, a LP é ferramenta de preservação e/ou aprofundamento da singularidade, importante distinção perante os povos da região. Esse idioma, que a larga maioria relata ser de uso generalizado na escola (aulas, atividades extracurriculares e convívio), é tido frequentemente como repositório de uma cultura que resulta do convívio secular e do laço político com uma comunidade linguística internacional, o que foi crucial para fazer vingar o direito de Timor à autodeterminação, através da pressão internacional executada pelos países de expressão portuguesa, nomeadamente Brasil e Portugal. A separação da LP ante à LI também foi percebida por alguns entrevistados como fator que permitiu ao grupo manter em segredo as suas fontes de identidade, herdadas e singulares, preservando perspectivas distintas sobre a realidade e protegendo o caráter distintivo do grupo, ou ainda a comunicação em segredo entre a guerrilha armada e o mundo.

A análise evidencia uma visão geral da língua como traço decisivo da identidade cultural (nacional), mostrando por que razão ela é vista pelas sociedades e por acadêmicos como mais do que uma ferramenta de comunicação, num quadro de notável simbolismo, em especial em contextos de inevitável oposição a outros povos. A LP, sem a qual as semelhanças com a parte indonésia da ilha se evidenciariam, é percebida como veículo fundamental da continuidade de um povo que acentuou a sua singularidade na junção de culturas, um território de encontro do consciente e subconsciente, assim como da herança e transformação, em diálogo permanente e, por vezes, controverso, entre o passado e o futuro.

Devemos ainda dizer que esta defesa da identidade timorense se faz sob um princípio nacionalista, num espírito ético e universalista, ao afirmar a sua identidade ligada aos países lusófonos em vez de reclamar uma atitude essencialista. Aliás, por tudo isto, será importante reconhecer, valorizar e respeitar na língua, conforme afirma Almeida (2017), uma semântica específica do contexto em que ela vive e evolui, importante para a defesa da dignidade dos povos, o entendimento mútuo e a construção de melhores relações, abrindo as portas, como se diz, a um mundo de possibilidades de cooperação e, aditaríamos, de fraternidade e paz.

Num trabalho desta natureza, o valor do que dizem os entrevistados, os dados, depende tanto do número de ocorrências como da riqueza e da profundidade do que é afirmado, o que pode depender da vivência do entrevistado, da sua capacidade de reflexão sobre o tema ou mesmo da capacidade do pesquisador para identificar e interpretar. Por isso, ainda que existam poucas falas em algumas subcategorias, muitas delas podem ser relevantes no que se refere à importância de uma língua para a resistência de um povo num contexto de opressão física, psicológica, mas também cultural. É bastante impressiva a fala de um entrevistado sobre a importância de se falar o português num contexto em que o invasor humilhava e as pessoas se sentiam inferiores, afirmando que "aquilo que nos fez sentir seres humanos e termos uma dignidade elevada foi o fato de sabermos português e eles não saberem nada!"

Ensinar numa língua entranhada na cultura há séculos e que garante acesso ao conhecimento universal, promovendo um ambiente escolar em que ela é usada em todas 
as situações, quando a força estrangeira tudo fez para indonesiar, parece ter criado um território de liberdade para a afırmação de uma identidade própria. A língua, mais do que instrumento de comunicação e acesso ao conhecimento, permitiu escrever de forma sublinhada o direito político de um povo à sua diferença, à sua dignidade. Nas mentes e corações dos seus promotores, como de todos os que deram vida à escola, parece haver uma visão identitária na senda do que afirmou um dia o filósofo George Santayana (apud Almeida, 2014, p. 29): “os pés de um homem devem estar plantados na sua terra, mas os seus olhos devem mirar o mundo todo".

Para terminar, recorda-se que se trata de construir uma imagem do que a escola foi a partir de representações que os entrevistados têm dela várias décadas depois. Em termos de pesquisa será ainda importante aprofundar a análise, nomeadamente relacionando os aspectos relativos à língua com outros traços distintivos da identidade timorense ali promovidos.

\section{Referências}

ALMEIDA, Onésimo Teotónio. A obsessão da portugalidade. Lisboa: Quetzal, 2017.

ALMEIDA, Onésimo Teotónio. A questão da identidade nacional na escrita portuguesa contemporânea. Hispania, Birmingham, v. 74, n. 3, p. 492-500, 1991.

ALMEIDA, Onésimo Teotónio. Mínima Azorica: o meu mundo é deste reino. Lajes do Pico: Companhia das Ilhas, 2014.

ALMEIDA, Onésimo Teotónio. National identity: a revisitation of the portuguese debate. National University of Ireland Maynooth Papers in Spanish, Portuguese and Latin American Studies, Maynooth, n. 5, p. 1-19, 2002.

AMAD0, João. A investigação em educação e seus paradigmas. In: AMAD0, João (coord.). Manual de investigação qualitativa em educação. Coimbra: Universidade de Coimbra, 2013. p. 19-71.

AMAD0, João; FREIRE, Isabel. Estudo de caso na investigação em educação. In: AMAD0, João. (coord.). Manual de investigação qualitativa em educação. Coimbra: Imprensa da Unniversidade, 2013. p. 121-143.

ANDERSON, Benedict. Imagined communities: reflections on the origin and spread of nationalism. New York: Verso, 2006.

BARKER, Ernest. National character and the factors in its formation. London: Methuen, 1927.

BECK, Margie. The context and history of the education sector in Timor-Leste. In: EARNEST, Jaya; BECK, Margie; CONNELL, Lorraine (ed). Rebuilding education \& health in a post-conflict transitional nation: case studies from Timor-Leste. Rotherdam: Sense, 2008. p. 3-8.

BERENSKOETTER, Felix. Identity in international relations. In: DENEMARK, Robert Allen (ed.). The international studies encyclopedia. v. 6. Oxford: Wiley-Blackwell, 2017. p. 3594-3611. 
BERQUE, Jacques. Identités collectives et sujets de l'histoire. In: MICHAUD, Guy (dir.). Identité collective et relations inter-culturelles. Bruxelles: Complexe, 1978. p. 11-18.

BOGDAN, Robert; BIKLEN, Sari Knopp. Qualitative research for education: an introduction to theory and methods. Boston: Allyn and Bacon, 1992.

CALHOUN, Craig. Nationalism and ethnicity. Annual Review of Sociology, San Mateo, v. 19, p. 211-239, 1993.

CASTELS, Manuel. The information age: economy, society and culture: the power of identity. v. 2. Oxford: Blackwell, 2010.

COUTINHO, Clara Pereira. Metodologia de investigação em ciências sociais e humanas: teoria e prática. 2. ed. Coimbra: Almedina, 2016.

CROSSLEY, Michael; VULLIAMY, Graham (ed.). Qualitative educational research in developing countries: current perspectives. New York: Routledge, 1997.

EDWARDS, John. Language, society, and identity. Oxford: Basil Blackwell, 1985.

FEARON, James D. What is identity (as we now use the word)? Stanford: Stanford University, 1999. Disponível em: https://web.stanford.edu/group/fearon-research/cgi-bin/wordpress/wp-content/ uploads/2013/10/What-is-Identity-as-we-now-use-the-word-.pdf. Acesso em: 16 abr. 2019.

FELGUEIRAS, João. As raízes da resistência. Camões: Revista de Letras e Culturas Lusófonas, n. 14, p. 42-49, 2001.

FELGUEIRAS, João; MARTINS, José Alves. Nossas memórias de vida em Timor. Braga: A. 0., 2006.

GELLNER, Ernest. Nações e nacionalismo. Lisboa: Gradiva, 1993.

GILROY, Paul. Diaspora and the detours of identity. In: WOODWARD, Kathryn (ed.). Identity and difference. London: Sage; Milton Keynes: The Open University, 1997. p. 299-346. (Culture, media and identities series).

GUERRA, Isabel Carvalho. Pesquisa qualitativa e análise de conteúdo: sentidos e formas de uso. Cascais: Princípia, 2006.

GUIBERNAU, Montserrat. Nacionalismos: 0 estado nacional e o nacionalismo no século XX. Rio de Janeiro: Zahar, 1997.

GUTERRES, Fátima. Timor: paraíso violentado. Lisboa: Lidel, 2014.

HALL, Stuart. The question of cultural identity. In: HALL, Stuart et al. (ed.). Modernity: an introduction to modern societies. Oxford: Blackwell, 1996. p. 596-634.

HOBSBAWM, Eric; RANGER, Terence (ed.). The invention of tradition. Cambridge: Cambridge University, 1984. 
HOPF, Ted. The promise of constructivism in international relations theory. International Security, Cambridge, v. 23, n. 1, p. 171-200, 1998.

HULL, Geoffrey. Timor Leste: identidade, língua e política nacional. Lisboa: Instituto Camões, 2001.

JENKINS, Richard. Social identity. 2. ed. New York: Routledge, 2004.

KEDOURIE, Elie. Nationalism. Oxford: Blackwell, 1998.

LIPIANSKY, Edmond Marc. L’âme française ou le National-Libéralisme. Paris: Anthropos, 1979.

LIPIANSKY, Edmond Marc. L'identité française: représentations, mythes, idéologies. La Garenne-Colombes: L'Espace Européen, 1991.

MAGALHÃES, António Barbedo de. Timor Leste na encruzilhada da transição indonésia. Lisboa: Gradiva: Fundação Mário Soares, 1999.

MATTOSO, José. Dignidade: Konis Santana e a resistência timorense. Lisboa: Temas e Debates, 2005.

MAYALL, James. Nationalism and international society. Cambridge: Cambridge University, 1993.

PARDAL, Luís; LOPES, Eugénia Soares. Métodos e técnicas de investigação social. Porto: Areal, 2011.

PIRES, Paulo. Timor: labirinto da descolonização. Lisboa: Colibri, 2013.

REID, Thomas. On the intellectual powers of man. v. 1. Dublin: L. White, 1875.

SCRUTON, Roger. The meaning of conservatism. Harmondsworth: Penguin, 1980.

SMITH, Anthony D. Biblical beliefs in the shaping of modern nations. Nations and Nationalism, Hoboken, v. 21, n. 3, p. 403-422, $2015 a$.

SMITH, Anthony D. Nationalism in the Twentieth Century. Canberra: Australian University, 1979.

SMITH, Anthony D. Nations before nationalism? Myth and symbolism in John Armstrong's perspective. Nations and Nationalism, Hoboken, v. 21, n. 1, p. 165-170, 2015b.

STAKE, Robert. A arte da investigação com estudos de caso. 3. ed. Lisboa: Fundação Calouste Gulbenkian, 2012.

STEINER, George. After Babel: aspects of language and translation. Oxford: Oxford University, 1992.

TEMPO. Closing down a leftover from Portugal, 7 December. In: ETAN. East Timor Action Network (org.). Articles on East Timor massacre from Peacenet and Associated Networks. [S. I.]: ETAN, 1991. p. 13. (East Timor document collection; v. 6).

THIESSE, Anne-Marie. A criação das identidades nacionais. Lisboa: Temas e Debates, 2000. 
THOMAZ, Luís Filipe F. Reis. Babel Loro Sa'e: o problema linguístico de Timor-Leste. Lisboa: Instituto Camões, 2002.

TIMOR-LESTE. Constituição da República Democrática de Timor-Leste. Díli: Parlamento Nacional da República Democrática de Timor-Leste, 2002.

TSUI, Amy Bik May; TOLLEFSON, James William. Language policy and the construction of national cultural identity. In: TSUl, Amy Bik May; TOLLEFSON, James William (ed.). Language policy, culture, and identity in Asian contexts. New York: Lawrence Erlbaum Associates, 2007. p. 1-21.

VINUTO, Juliana. A amostragem em bola de neve na pesquisa qualitativa: um debate em aberto. Temáticas, Campinas, v. 22, n. 44, p. 203-220, 2014.

VYGOTSKY, Lev Semionovitch. Mind in society: the development of higher psychological processes. Cambridge: Harvard University, 1978.

WILLIS, Jerry. Qualitative research methods in education and educational technology. Charlotte: Information Age, 2008.

XIMENES BELO, Carlos Filipe. A língua portuguesa em Timor-Leste. Agência Ecclesia: agência de notícias da igreja católica em Portugal, Lisboa, 2008. Disponível em: https://agencia.ecclesia.pt/portal/alingua-portuguesa-em-timor-leste/. Acesso em: 11 mar. 2019.

Recebido em: 12.02.2020

Revisado em: 21.07.2020

Aprovado em: 14.09.2020

Ângelo Ferreira é investigador do Centro de Investigação em Didática e Tecnologia na Formação de Formadores (CIDTFF). É doutor em educação com tese realizada sob orientação de António Neto-Mendes (Universidade de Aveiro, Portugal) e Onésimo Teotónio Almeida (Brown University, EUA). 